\title{
Effect of cocoa-enriched diets on lymphocytes involved in adjuvant arthritis in rats
}

\author{
Sara Ramos-Romero ${ }^{1}$, Francisco J. Pérez-Cano ${ }^{1,2}$, Cristina Castellote ${ }^{1,2,3}$, Margarida Castell ${ }^{1,2 *}$ \\ and Àngels Franch ${ }^{1,2,3}$ \\ ${ }^{1}$ Departament de Fisiologia, Facultat de Farmàcia, Universitat de Barcelona, Avinguda Joan XXIII s/n, Edifici B, $3{ }^{a}$ planta, \\ 08028 Barcelona, Spain \\ ${ }^{2}$ Institut de Recerca en Nutrició i Seguretat Alimentària (INSA-UB), Barcelona, Spain \\ ${ }^{3}$ CIBER Epidemiología y Salud Pública, Barcelona, Spain
}

(Received 29 October 2010 - Revised 4 May 2011 - Accepted 4 May 2011 - First published online 15 July 2011)

\section{Abstract}

Cocoa and its flavonoids have potential anti-inflammatory properties in vitro and in acute inflammation models in vivo. The aim of the present study was to ascertain the effects of two cocoa-enriched diets on adjuvant arthritis (AA) in rats, considering not only clinical and biochemical inflammatory indices, but also antibody response and lymphocyte composition. Female Wistar rats were fed with a 5 or $10 \%$ cocoa-enriched diet beginning 2 weeks before arthritis induction and until the end of the study. AA was induced by an intradermal injection of heat-killed Mycobacterium butyricum suspension. The hind-paw swelling (plethysmometry), serum anti-mycobacterial antibody concentration (ELISA), blood and inguinal lymph node lymphocyte subset percentage (flow cytometry), and IL-2, interferon $\gamma$ and $\mathrm{PGE}_{2}$ released from splenocytes (ELISA) were assessed. Although the cocoa diets had no significant effect on hind-paw swelling, a tendency to reduce it was observed at the end of the study. Cocoa-enriched diets were able to decrease the serum anti-mycobacterial antibody concentration and the splenocyte $\mathrm{PGE}_{2}$ production, as well as the proportion of T-helper $\left(\mathrm{T}_{\mathrm{h}}\right)$ lymphocytes in blood and regional lymph nodes, which probably includes cells responsible for the arthritic process. The cocoa diets prevented a decrease in the proportion of regulatory T-cells in blood and a disequilibrium between inguinal lymph node natural killer (NK) $\mathrm{CD}^{+}$and $\mathrm{NK}^{\mathrm{CD}} 8^{-}$subsets. In conclusion, the cocoa-enriched diets during AA were not able to significantly decrease joint inflammation but modified $\mathrm{T}_{\mathrm{h}}$-cell proportions and prevented specific antibody synthesis.

Key words: Cocoa flavonoids: Adjuvant arthritis: T-helper lymphocytes: Anti-mycobacterial antibodies

In ancient civilisations, cocoa (Theobroma cacao seed product) used to be consumed for its beneficial effects on health $^{(1-3)}$, but it changed from being consumed for medicinal purposes to being eaten as a confectionery in modern society. Nowadays, there is a resurgence of interest in the health properties of cocoa and its derivatives. Much scientific evidence has suggested that the beneficial effects of cocoa are associated with its flavonoids ${ }^{(4)}$. Cocoa mainly contains flavan-3-ols such as $(-)$-epicatechin and $(+)$-catechin $(0 \cdot 20-3.50 \mathrm{mg} / \mathrm{g})$, and their polymers called proanthocyanidins $(2 \cdot 16-100 \mathrm{mg} / \mathrm{g})^{(5,6)}$, which, unlike other products such as tea, apples, grapes or red wine, can have up to ten linked units of flavanol monomers ${ }^{(7)}$. Large proanthocyanidins are less efficiently absorbed in the small intestine than shorter flavanols, and as a result they reach to the colon, where they are transformed by intestinal microbiota and absorbed through the intestinal barrier ${ }^{(8)}$. In consequence, the beneficial effect of these phytochemicals could be mainly attributed to metabolites derived from the microbial catabolism of proanthocyanidins $^{(9,10)}$. Large proanthocyanidins in the colon may have an important local function neutralising oxidants and carcinogenic compounds all along the gut ${ }^{(11)}$. On the other hand, in addition to flavanols, quercetin and its derivatives, such as quercitrin, isoquecitrin, rutin, naringenin, luteolin and apigenin, are also present in cocoa in smaller quantities $^{(12)}$.

Despite some in vitro studies, the influence of cocoa on the immune system is still relatively unknown. Previously,

Abbreviations: AA, adjuvant arthritis; C5-AA, arthritic animals fed a 5\% cocoa-enriched diet; C10-AA, arthritic animals fed a 10\% cocoa-enriched diet; FBS, fetal bovine serum; IFN- $\gamma$, interferon $\gamma$; ILN, inguinal lymph node; mAb, monoclonal antibodies; Mb, Mycobacterium butyricum; NK, natural killer; NKT, natural killer T; REF, healthy animals fed a standard diet; REF-AA, arthritic animals fed a standard diet; RPMI-FBS, Roswell Park Memorial Institute-1640 media containing $10 \%$ fetal bovine serum; $\mathrm{T}_{\mathrm{act}}$, activated T-helper; $\mathrm{T}_{\mathrm{c}}$, T-cytotoxic; TCR, T-cell receptor; $\mathrm{T}_{\mathrm{h}}$, T-helper; $\mathrm{T}_{\text {reg }}$, regulatory $\mathrm{T}$-helper. 
we reported that a cocoa-enriched diet modifies lymphocyte composition and function in several lymphoid tissues in rats $^{(13,14)}$. Specifically, a $10 \%$ cocoa diet given to young rats over 3 weeks increases the proportion of B-cells in the spleen $^{(13)}$, mesenteric lymph nodes and also in Peyer's patches $^{(14)}$, whereas it down-regulates serum $\operatorname{IgG}, \operatorname{IgM}$ and IgA production ${ }^{(13)}$. Moreover, specific antibody concentration against ovalbumin significantly decreased in immunised rats fed cocoa $^{(15)}$. On the other hand, a cocoa-enriched diet reduces $\mathrm{CD}_{4}^{+}$T-helper $\left(\mathrm{T}_{\mathrm{h}}\right)$ lymphocyte proportion in the spleen and mesenteric lymph nodes but its IL-2 secretion, a cytokine with an autocrine effect producing $\mathrm{T}_{\mathrm{h}}$ proliferation, is not modified ${ }^{(13)}$.

Rheumatoid arthritis is an inflammatory autoimmune disease mainly mediated by $\mathrm{T}_{\mathrm{h}}$ cells ${ }^{(16)}$. Adjuvant arthritis (AA) is an experimental model in rats of human rheumatoid arthritis that has been widely used for the screening of anti-inflammatory drugs ${ }^{(17,18)}$. The pathogenesis of the adjuvant arthritic process seems to be mainly related to $\mathrm{CD}^{+}{ }^{+} \mathrm{T}$-cells, because administration of monoclonal antibodies (mAb) against CD4 can prevent AA development ${ }^{(19)}$ and also ameliorate established $\mathrm{AA}^{(20)}$.

Inflammation is a complex biological response by vascular tissues to harmful stimuli to remove the injurious agent, as well as to initiate the tissue reparation process ${ }^{(21)}$. Studies performed in vitro have shown the anti-inflammatory properties of isolated flavonoids. In this sense, epicatechin and isoquercitrin decrease TNF- $\alpha$ and monocyte chemoattractant protein-1 production by lipopolysaccharide-stimulated macrophages ${ }^{(22)}$. Furthermore, quercetin inhibits cyclo-oxygenase pathways and $\mathrm{PGE}_{2}$ synthesis in the Chang liver cell line ${ }^{(23)}$ and in human lymphocytes ${ }^{(24)}$. In addition, some studies have reasserted the anti-inflammatory capacity of isolated flavonoids in vivo. Subcutaneous or intravenous injections of catechin and epicatechin produce a significant reduction of a local acute inflammation induced in rats ${ }^{(25)}$.

The effect of cocoa on the inflammatory response is more complex than that of flavonoids because it contains a mix of diverse compounds. There are studies about the in vitro effect of cocoa on pro-inflammatory cytokine and chemokine release, generating controversial results. While some cocoa flavonoid fractions increase the production of pro-inflammatory cytokines in peripheral blood mononuclear cells ${ }^{(26-29)}$; a complete cocoa extract decreases the TNF- $\alpha$, monocyte chemoattractant protein-1 and nitric oxide production by macrophages ${ }^{(22)}$. In addition, peritoneal macrophages obtained from rats fed with cocoa for at least 1 week produce lower amounts of TNF- $\alpha$, IL- 6 , NO and reactive oxygen species $^{(13,30-32)}$. Moreover, in previous studies ${ }^{(30,31)}$, a cocoa suspension administered by the oral route for a week decreased the local hind-paw swelling induced by carrageenin and bradykinin in rats and reduced TNF- $\alpha$ concentration in inflammatory exudates. How cocoa metabolites down-regulate the inflammatory response remains to be established. Some in vitro studies have shown that flavonoids such as epicatechin, catechin, dimeric procyanidins and quercetin can modify the NF-кB pathway ${ }^{(33,34)}$ involved in the synthesis of inflammatory products.
Because cocoa inhibits the release of some inflammatory mediators in vitro, reduces acute local inflammation in rodent models and decreases the $\mathrm{T}_{\mathrm{h}}$-cell proportion in several lymphoid tissues in vivo, the aim of the present study was to determine the effects of two cocoa-enriched diets on AA. Specifically, we have taken into consideration not only clinical and biochemical inflammatory indices, but also antibody response and lymphocyte composition in two different compartments.

\section{Materials and methods}

\section{Animals}

A total of forty-five 9-week-old female Wistar rats were obtained from Harlan (Barcelona, Spain). Rats were housed three to four per cage in controlled temperature $\left(20 \pm 2{ }^{\circ} \mathrm{C}\right)$ and humidity (55\%) conditions in a $12 \mathrm{~h}$ light $-12 \mathrm{~h}$ dark cycle, with free access to food and water. Handling was done in the same time range to avoid the influence of biological rhythms. Studies were performed in accordance with the institutional guidelines for the care and use of laboratory animals established by the Ethical Committee for Animal Experimentation at the University of Barcelona and approved by the Catalonian Government.

\section{Induction and assessment of adjuvant arthritis}

To induce the arthritis process, rats were injected intradermally into the base of the tail with a suspension of $0.5 \mathrm{mg}$ heat-killed Mycobacterium butyricum (Mb; Difco, Detroit, MI, USA) in $0.1 \mathrm{ml}$ of liquid vaseline. AA was clinically assessed by means of hind-paw volume with a water plethysmometer (LI 7500; Letica, Barcelona, Spain). Left and right hind-paw volumes were measured just before AA induction (on day 0), daily during the second week post-induction, and every other day until the end of the study. All determinations were performed in a blinded manner. Articular inflammation was expressed as a percentage of increase in both hind-paw volumes with respect to their value on day 0 . On day 14, animals were classified as arthritic if the increase in hind-paw volumes was higher than the volume increase media of healthy animals fed a standard diet (REF) plus two times its standard deviation.

\section{Experimental design}

The standard diet corresponded to the American Institute of Nutrition-93M formulation, which provides the nutrients required for optimal rat maintenance and was used as the reference diet (Table 1). Partially defatted Natural Forastero cocoa (Nutrexpa, Barcelona, Spain) was used to manufacture cocoa chows. This cocoa powder contained $22 \%$ proteins, $16 \%$ carbohydrates, $11 \%$ lipids and $25.5 \%$ fibre, and $21.2 \mathrm{mg}$ of total phenols/g according to the Folin-Ciocalteu method. Cocoa diets (5 and 10\%) were prepared partially removing maize starch, soyabean oil, cellulose and casein from American Institute of Nutrition-93M standard starch and adding 50 or 
Table 1. Composition of the experimental diets $(\mathrm{g} / \mathrm{kg})^{*}$

\begin{tabular}{lccc}
\hline & $\begin{array}{c}\text { Standard chow } \\
\text { (AIN-93M, } \\
\text { g/kg) }\end{array}$ & $\begin{array}{c}5 \% \text { Cocoa- } \\
\text { enriched } \\
\text { chow }(\mathrm{g} / \mathrm{kg})\end{array}$ & $\begin{array}{c}10 \% \text { Cocoa- } \\
\text { enriched } \\
\text { chow }(\mathrm{g} / \mathrm{kg})\end{array}$ \\
\hline Casein & 140 & 129 & 118 \\
L-Cys & 1.8 & 1.8 & 1.8 \\
Maize starch & 465.69 & 457.69 & 449.69 \\
Maltodextrin & 155 & 155 & 155 \\
Sucrose & 100 & 100 & 100 \\
Soyabean oil & 40 & 34.5 & 29 \\
Cellulose & 50 & 37.25 & 24.5 \\
Mineral mix (TD94046) & 35 & 35 & 35 \\
Vitamin mix (TD94047) & 10 & 10 & 10 \\
Choline bitartrate & 2.5 & 2.5 & 2.5 \\
tert-Butylhydroquinone & 0.008 & 0.008 & 0.008 \\
Natural cocoa powder & - & 50 & 100 \\
Total energy (kJ/kg diet) & 15069.6 & 15069.6 & 15069.6 \\
\hline
\end{tabular}

AIN, American Institute of Nutrition.

* The cocoa powder used contained $22 \%$ proteins, $16 \%$ carbohydrates, $11 \%$ lipids and $25.5 \%$ fibre, and $21.2 \mathrm{mg}$ of total phenols/g according to the Folin-Ciocalteu method.

$100 \mathrm{~g} \mathrm{cocoa} / \mathrm{kg}$ of chow, respectively (Table 1 ). In consequence, the resulting chow had the same proportion of carbohydrates, lipids, proteins and total energy as the standard diet. Following the conversion of animal doses into human equivalent doses described by Reagan-Shaw et al. ${ }^{(35)}$, the $5 \%$ cocoa-enriched diet was equivalent to $0.454 \mathrm{~g}$ cocoa/ $\mathrm{kg}$ human per d (27.25 g cocoa for a $60 \mathrm{~kg}$ individual) and the $10 \%$ cocoa-enriched diet was equivalent to $0.908 \mathrm{~g}$ $\mathrm{cocoa} / \mathrm{kg}$ human per $\mathrm{d}$ ( $54.5 \mathrm{~g}$ cocoa for a $60 \mathrm{~kg}$ individual).

Animals were randomly distributed into four different experimental groups: REF ( $n$ 12); arthritic animals fed a standard diet (REF-AA; $n$ 11); arthritic animals fed a 5\% cocoa-enriched diet (C5-AA; $n$ 11); arthritic animals fed a 10\% cocoa-enriched diet (C10-AA; $n$ 11). The REF and REF-AA groups were fed with the standard diet, the C5-AA group was fed with the $5 \%$ cocoa-enriched diet and the C10-AA group with the $10 \%$ of cocoa-enriched diet. The diets began $14 \mathrm{~d}$ before arthritis induction and lasted until the end of the study, a total of 6 weeks (Fig. 1).

At weeks 2 and 3 post-induction, the animals were anaesthetised by isoflurane inhalation in order to collect $100 \mu \mathrm{l}$ of blood by tail vein puncture for serum anti-Mb antibody determination (Fig. 1). On day 28 post-induction, the animals were anaesthetised with ketamine $(90 \mathrm{mg} / \mathrm{kg}$; Merial, Lyon, France) and xylazine $(10 \mathrm{mg} / \mathrm{kg}$; Bayer HealthCare, Kiel, Germany) intraperitoneally and killed by total exsanguination by cardiac puncture. Blood and lymphoid tissues such as spleen, representative of the systemic immune tissues, and inguinal lymph nodes (ILN), that drain the knee joint synovia, one of the most affected tissues in AA, were obtained. An aliquot of each blood sample was used to automatically count the leucocytes by using a Coulter Counter JT haemocytometer (Hialeah, FL, USA) calibrated for rat blood. The differential white blood count was obtained by manual enumeration of May-Grünwald-Giemsa-stained blood cell smears.

\section{Cell isolation from peripheral blood, lymph nodes and spleen}

On the day of killing, blood was immediately treated with $10 \mathrm{~g} / \mathrm{l} \mathrm{NH}_{4} \mathrm{Cl}$ solution to lyse erythrocytes. After washing once with PBS containing 2\% fetal bovine serum (FBS; PAA, Pashing, Austria) and $0 \cdot 1 \% \mathrm{NaN}_{3}$, peripheral blood cells were ready for immunofluorescence staining.

ILN and spleen were broken up by passing the tissues through a steel mesh (Cellector ${ }^{\mathrm{TM}}$; Bellco, Vertieb, Austria) with Roswell Park Memorial Institute-1640 media containing $10 \%$ FBS (RPMI-FBS). Cells were then centrifuged ( $540 \mathrm{~g}$, $10 \mathrm{~min}, 4^{\circ} \mathrm{C}$ ) and resuspended in PBS. Then, lymphocytes from ILN were ready for immunofluorescence staining. The spleen cells underwent an erythrocyte lysis by adding distilled water for $5 \mathrm{~s}$ and restoring tonicity by adding PBS ten times. Then, cells were washed and resuspended with RPMIFBS containing $100000 \mathrm{U} / 1$ penicillin and $0 \cdot 1 \mathrm{~g} / 1$ streptomycin 2 mm-L-glutamine (Sigma Chemical Company, St Louis, MO, USA), and 0.05 mm-2-mercaptoethanol (Merck KGaA, Darmstadt, Germany) to be cultured. Number and viability were determined by acridine orange and ethidium bromide (Sigma) staining followed by fluorescence light microscopical analysis.

\section{Immunofluorescence staining and flow cytometry analysis}

Lymphocyte phenotype was determined just after cell isolation by double or triple staining, using fluorochrome-conjugated $\mathrm{mAb}$ followed by flow cytometry analysis. Mouse anti-rat $\mathrm{mAb}$ conjugated to fluorescein isothiocyanate, phycoerythrin, peridinin chlorophyll protein or allophycocyanin used here included the following: anti-T-cell receptor (TCR) $\alpha \beta$ (R73), anti-TCR $\gamma \delta$ (V65), anti-NKR-P1A (10/78), anti-CD4 (OX-35), anti-CD25 (IL-2R $\alpha$ chain, OX-39), anti-CD8 $\alpha$ (OX-8), anti-

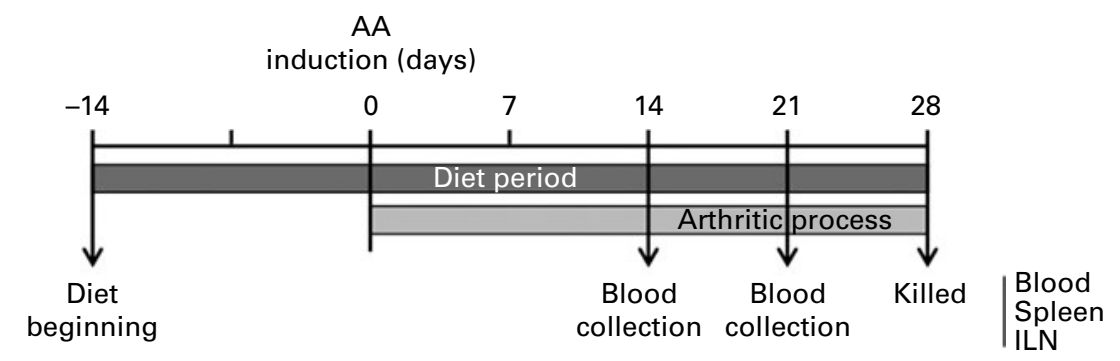

Fig. 1. Diagram of the experimental design beginning $14 \mathrm{~d}$ before adjuvant arthritis (AA) induction until day 28 post-induction. ILN, inguinal lymph node. 
CD45RA (OX-33), anti-CD81 (Eat2) (BD Biosciences, Erembodegem, Belgium) and anti-Foxp3 (FJK-16a; eBioscience, Frankfurt, Germany). Extracellular staining was performed in $5 \times 10^{5}$ cells by saturating concentrations of fluorochrome$\mathrm{mAb}$ in PBS containing $1 \% \mathrm{FBS}$ and $0.1 \% \mathrm{NaN}_{3}$ (30 min, $4^{\circ} \mathrm{C}$, in the dark). A negative control staining using an isotype-matched mAb was included for each sample. For intracellular staining, cells previously labelled with anti-CD4phycoerythrin and anti-CD25-fluorescein isothiocyanate mAb were treated with a Foxp3 fixation/permeabilisation kit (eBioscience). Then, intracellular staining with anti-Foxp3-APC $\mathrm{mAb}$ was carried out in the same conditions as extracellular staining. All stained cells were fixed with $0.5 \% p$-formaldehyde and stored at $4^{\circ} \mathrm{C}$ in the dark. Analysis was performed using a Cytomics FC500-MPL cytometer (Beckman Coulter, Miami, FL, USA).

Lymphocyte subsets were defined in the cytometer as follows: $\mathrm{T} \alpha \beta\left(\mathrm{TCR} \alpha \beta^{+} \mathrm{NKR}^{\mathrm{P} 1 \mathrm{~A}^{-}}\right), \mathrm{T} \gamma \delta\left(\mathrm{CD}^{+}{ }^{+} \mathrm{TCR} \gamma \delta^{+}\right)$, $\mathrm{B}\left(\mathrm{CD} 45 \mathrm{RA}^{+}\right)$, natural killer (NK; NKR-P1A ${ }^{+}$TCR- $\alpha \beta^{-}$), 든 natural killer $\mathrm{T}\left(\mathrm{NKT} ; \mathrm{NKR}^{\mathrm{P} 1 \mathrm{~A}^{+}} \mathrm{TCR} \alpha \beta^{+}\right), \mathrm{T}_{\mathrm{h}}\left(\mathrm{CD} 4^{+}\right.$ TCR $\left.\alpha \beta^{+}\right)$, T-cytotoxic $\left(\mathrm{T}_{\mathrm{c}} ; \mathrm{TCR} \alpha \beta^{+} \mathrm{CD} 8 \alpha^{+} \mathrm{NKR} \mathrm{P} 1 \mathrm{~A}^{-}\right), \mathrm{T}_{\mathrm{h}} 2$ $\left(\mathrm{CD} 4^{+} \mathrm{TCR} \alpha \beta^{+} \mathrm{CD} 81^{+}\right)$, activated $\mathrm{T}_{\mathrm{h}}\left(\mathrm{T}_{\mathrm{act}} ; \mathrm{CD} 4^{+} \mathrm{CD} 25^{+}\right.$ Foxp $3^{-}$) and regulatory $\mathrm{T}_{\mathrm{h}}\left(\mathrm{T}_{\text {reg; }} \mathrm{CD}^{+}{ }^{+} \mathrm{CD} 25^{+}\right.$Foxp $\left.^{+}\right)$. Results are expressed as a percentage of positive cells in the lymphocyte population, selected previously according to the forward and side scatter characteristics of a cellular suspension that includes positive cells stained with anti-TCR, anti-NKR-P1A and anti-CD45RA. In some cases, results are presented as a percentage of positive cells in a specific lymphocyte subset ( $\mathrm{T}, \mathrm{T}_{\mathrm{h}}$ or NK cells).

\section{Anti-Mycobacterium butyricum antibodies in serum}

Anti-Mb antibody levels in sera were determined by using an indirect ELISA technique, as described previously ${ }^{(36)}$. Briefly, polystyrene microELISA plates (Nunc Maxisorp, Wiesbaden, Germany) were incubated with a soluble protein fraction of $\mathrm{Mb}$ in PBS $(3 \mu \mathrm{g} / \mathrm{ml})$. After sample incubation, peroxidaseconjugated goat anti-rat Ig antibodies (BD Biosciences) were used. Since standards were not available, several dilutions of pooled sera from REF-AA animals were added to each plate. This pool was arbitrarily assigned $64000 \mathrm{U} / 1$ anti-Mb antibodies.

\section{Spleen cell culture and cytokines and $P G E_{2}$ secretion}

Splenocytes were cultured at $3 \times 10^{6}$ cells $/ \mathrm{ml}$ in twentyfour-well plates. Cells were stimulated with $\mathrm{Mb}(10 \mu \mathrm{g} / \mathrm{ml})$ for 24,48 or $72 \mathrm{~h}$ or remained without a stimulus. IL-2 concentration was quantified in the $24 \mathrm{~h}$ supernatant using a rat ELISA set (BD Biosciences). Interferon $\gamma$ (IFN- $\gamma$ ) concentration was determined in the $72 \mathrm{~h}$ supernatant with a Biosource ELISA set (Nivelles, Belgium). $\mathrm{PGE}_{2}$ concentration was determined in the $48 \mathrm{~h}$ supernatant by a competitive immunoassay kit from Cayman Chemicals (Ann Arbor, MI, USA) according to the manufacturers' recommendations. The time points to perform these analyses were established in a preliminary study by determining the maximal concentrations of these analytes in our culture conditions.

\section{Statistics}

The software package SPSS 16.0 (SPSS, Inc., Chicago, IL, USA) was used for statistical analysis. Levene's and KolmogorovSmirnov's tests were applied to assay variance equality and normal distribution of the studied groups, respectively. The one-way ANOVA followed by Scheffé's post hoc significance test was applied when the assumptions of normality and equal variance were met. In the opposite case, non-parametric tests (Kruskal-Wallis and Mann-Whitney $U$ ) were used to assay significance. Significant differences were accepted when $P<0.05$.

\section{Results}

\section{Effect of the cocoa diet on body weight and articular} inflammation

At the beginning of the study, body weight was $165 \cdot 2$ (SEM $1 \cdot 1) \mathrm{g}$ for all the studied groups. After 6 weeks of the diet, body weight was 231.8 (SEM 3.6) g for the REF group, 200.2 (SEM 5.4) g for the REF-AA group, 198.9 (SEM 2.4) $\mathrm{g}$ for the C5-AA group and 192.9 (SEM 4.0) g for the C10-AA group. Therefore, regardless of the diet, at day 28 post-induction, all AA animals presented similar body weight, which was lower than that of healthy animals $(P<0.05)$.

On day 14 post-induction, arthritis incidence was over $92 \%$ for the reference arthritic group (REF-AA), similar to that found in both cocoa-fed groups (C5-AA and C10-AA). The time course of hind-paw volume increase after arthritis induction is summarised in Fig. 2(a). Paw volume reached a maximum increase of $130 \%$ in the REF-AA group on day 21 post-induction. Animals from the C5-AA group displayed a lower paw volume increase than the reference group from day 16 to 28 post-induction, but differences were not statistically significant. On the last day of the study, the C5-AA volume increase was reduced by $32 \%$ of that of the REF-AA group (Fig. 2(b)). Animals from the C10-AA group showed a paw oedema pattern similar to the REF-AA group, but on the last day of the study, the values were $28 \%$ lower than those of the REF-AA (Fig. 2(b)).

\section{Effect of the cocoa diet on peripheral blood lymphocyte subsets in adjuvant arthritis rats}

AA induced leucocytosis due to a neutrophil increase while the lymphocyte counts remained in the blood (Table 2). Alterations induced by AA were not modified by the cocoa diet.

Percentages of blood $\mathrm{T} \alpha \beta, \mathrm{T} \gamma \delta$, B, and NK lymphocytes did not change significantly in the REF-AA group (Fig. 3(a)) In the case of arthritic rats, all groups showed lower blood NKT cell percentages than the reference healthy animals (REF). Moreover, the blood T $\alpha \beta$ cell percentage in animals 
(a)

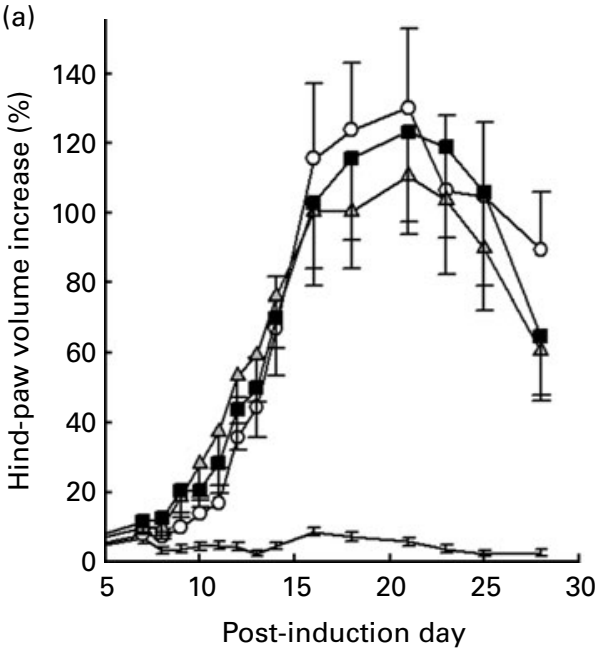

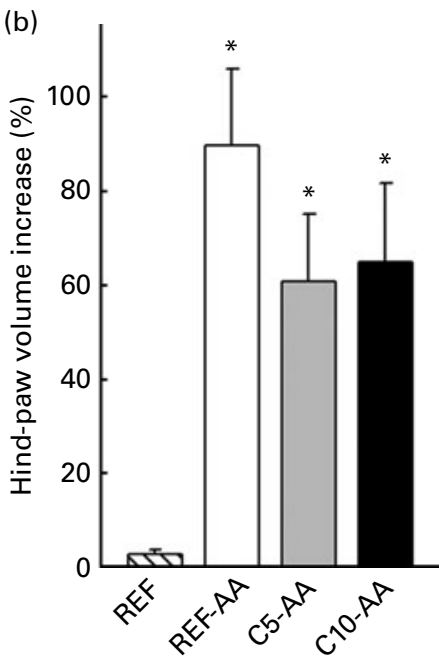

Day 28 post-induction

Fig. 2. Effect of cocoa diets on the clinical evolution of adjuvant arthritis (AA) evaluated by hind-paw volume increase, measured by a water plethysmometer. (a) Time course of AA (expressed as a percentage of increase in both hind-paw volumes with respect to their value on day 0 ): - , healthy animals fed a standard diet (REF); -O—, arthritic animals fed a standard diet (REF-AA); $-\downarrow$, arthritic animals fed a $5 \%$ cocoa-enriched diet (C5-AA); $\rightarrow-$, arthritic animals fed a $10 \%$ cocoa-enriched diet (C10-AA). (b) Percentage of hind-paw volume increase on the last day of the study. Values are means, with their standard errors represented by vertical bars $(n 11-12)$. * Mean values were significantly different from those of the REF group ( $P<0.05$; ANOVA followed by Scheffé's test).

fed a $10 \%$ cocoa-enriched diet decreased with respect to the REF-AA group $(P<0.05)$.

With regard to T-cell subsets (Fig. 3(b)), AA increased the $\mathrm{T}_{\mathrm{h}}$-cell proportion $(P<0.05)$ and decreased the $\mathrm{T}_{\mathrm{c}}$-cell percentage $(P<0 \cdot 05)$, resulting in a higher $\mathrm{T}_{\mathrm{h}}: \mathrm{T}_{\mathrm{c}}$ ratio in REF-AA animals compared with the REF group. Animals fed a $10 \%$ cocoa-enriched diet avoided this $\mathrm{T}_{\mathrm{h}}: \mathrm{T}_{\mathrm{c}}$ imbalance caused by the arthritic process $\left(P<0.05 v\right.$. REF-AA). The $\mathrm{T}_{\mathrm{h}}: \mathrm{T}_{\mathrm{c}}$ ratio in rats from the $5 \%$ cocoa diet group remained similar to that of REF animals, although values were not statistically different from the REF-AA group.

The proportion of $T_{h} 2$ cells was assessed by means of the presence of CD81 in $T_{h}$ cells. As shown in Fig. 3(c), the arthritic process did not affect the proportion of these cells, but both cocoa diets tended to reduce the $T_{h} 2$ proportion. Moreover, the AA process reduced the $\mathrm{T}_{\text {reg }}\left(\mathrm{CD} 4{ }^{+} \mathrm{CD} 25^{+}\right.$ Foxp $3^{+}$) cell proportion with respect to the REF group $(P<0.05$; Fig. 3(c)) and, interestingly, the 10\% cocoa-enriched diet avoided this alteration. $\mathrm{T}_{\text {act }}$ cell proportion, determined as $\mathrm{CD}^{+}{ }^{+} \mathrm{CD} 25^{+}$Foxp $^{-}$lymphocytes, was not affected by AA or the cocoa diets. NK cell subsets determined by CD8 phenotype (Fig. 3(d)) were not modified either by the AA process or cocoa intake.

\section{Effect of the cocoa diet on inguinal lymph node lymphocyte subsets in adjuvant arthritis rats}

The study of the main lymphocyte populations in ILN (Fig. 4(a)) revealed almost no changes induced by the arthritic process, as seen in the REF-AA group. There was only an increase in the low percentage of NKT cells $(P<0.05)$, which was also found to a lesser degree in the C5-AA and C10-AA groups. The cocoa diets decreased the B-cell population in AA rats in comparison with the REF group $(P<0.05$; Fig. 4(a)), and there was a concomitant increase in $\mathrm{T} \alpha \beta$ cells in the C5-AA group.

Although the arthritic process did not modify the proportion of $\mathrm{T}_{\mathrm{h}}$ and $\mathrm{T}_{\mathrm{c}}$ cells, both cocoa diets produced a decrease in the $\mathrm{T}_{\mathrm{h}}$-cell proportion in ILN $(P<0.05$; Fig. 4(b)).

On the other hand, neither arthritis nor the cocoa diets changed the $\mathrm{T}_{\mathrm{h}} 2$ cell profile in this tissue (Fig. 4(c)). Proportion of regional $\mathrm{T}_{\text {reg }}$ cell was not affected by the arthritic process or by the cocoa diets (Fig. 4(c)). In contrast, the proportion of $\mathrm{T}_{\text {act }}$ lymphocytes in arthritic animals increased significantly in ILN $(P<0.05)$

With respect to the NK cell population (Fig. 4(d)), the arthritic process increased more than twofold the $\mathrm{CD}^{+}: \mathrm{CD}^{-}$ratio in NK cells $(P<0 \cdot 05)$. The cocoa diets avoided this marked disequilibrium in ILN $(P<0 \cdot 05$, C10-AA $v$. REF-AA)

Table 2. Effect of adjuvant arthritis and cocoa diets on blood leucocyte, lymphocyte and neutrophil counts

(Mean values with their standard errors)

\begin{tabular}{|c|c|c|c|c|c|c|}
\hline \multirow{2}{*}{$\begin{array}{l}\text { Experimental } \\
\text { groups }\end{array}$} & \multicolumn{2}{|c|}{$\begin{array}{l}\text { Blood leuco- } \\
\text { cyte counts } \\
\left(\times 10^{9} / l\right)\end{array}$} & \multicolumn{2}{|c|}{$\begin{array}{l}\text { Blood lympho- } \\
\text { cyte counts } \\
\left(\times 10^{9} / I\right)\end{array}$} & \multicolumn{2}{|c|}{$\begin{array}{l}\text { Blood neutro- } \\
\text { phil counts } \\
\left(\times 10^{9} / l\right)\end{array}$} \\
\hline & Mean & SEM & Mean & SEM & Mean & SEM \\
\hline $\operatorname{REF}(n 12)$ & $2 \cdot 81$ & 0.63 & $2 \cdot 24$ & 0.63 & 0.46 & 0.08 \\
\hline REF-AA $(n 11)$ & $5 \cdot 81^{\star}$ & 0.95 & $2 \cdot 69$ & 0.48 & $2 \cdot 76^{\star}$ & 0.50 \\
\hline C5-AA (n 11) & $5 \cdot 88^{\star}$ & $0 \cdot 87$ & $2 \cdot 65$ & 0.51 & $2 \cdot 87^{\star \star}$ & 0.48 \\
\hline C10-AA $(n 11)$ & 5.06 & 1.00 & $2 \cdot 11$ & 0.56 & $2 \cdot 72^{\star}$ & 0.50 \\
\hline
\end{tabular}

REF, healthy animals fed a standard diet; REF-AA, arthritic animals fed a standard diet; C5-AA, arthritic animals fed a $5 \%$ cocoa-enriched diet; C10-AA, arthritic animals fed a $10 \%$ cocoa-enriched diet.

Mean values were significantly different from those of the REF group (one-way ANOVA followed by Scheffé's test): ${ }^{\star} P<0.05,{ }^{\star \star} P<0.001$. 

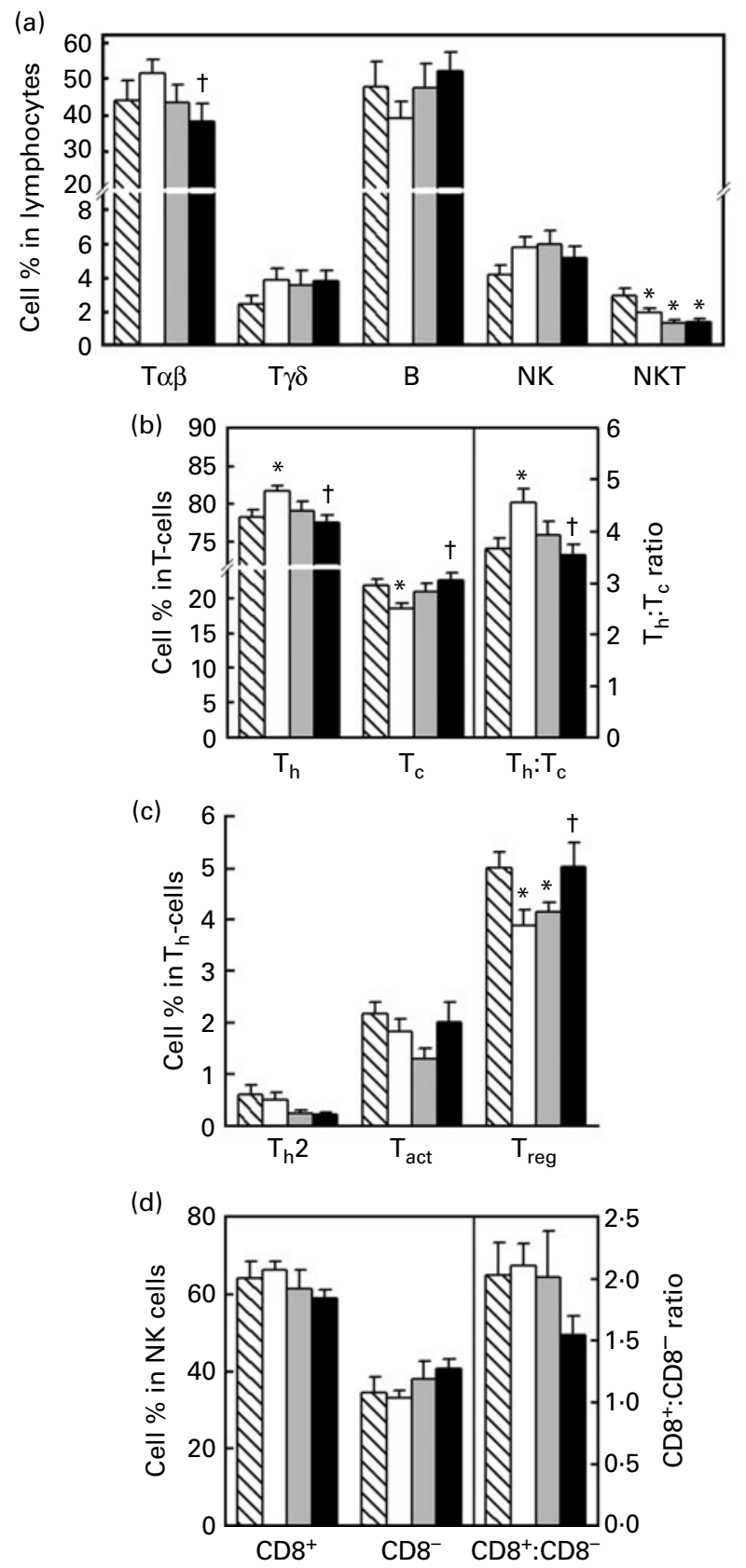

Fig. 3. Lymphocyte subset composition in rat blood, determined by double or triple staining, using fluorochrome-conjugated monoclonal antibodies followed by flow cytometry analysis. (a) $T \alpha \beta, T \gamma \delta, B$, natural killer (NK) and natural killer T (NKT) lymphocyte percentages. (b) T-helper $\left(T_{h}\right)$ and T-cytotoxic $\left(T_{c}\right)$ cell percentages in the T-cell population and $T_{h}: T_{c}$ ratio. (c) $T_{h} 2$, activated $T_{h}\left(T_{\text {act }}\right)$ and regulatory $T_{h}\left(T_{\text {reg }}\right)$ percentages in the $T_{h}$ subset. (d) $\mathrm{CD}^{+}$and $\mathrm{CD} 8^{-}$cell percentages in NK lymphocytes. Values are means, with their standard errors represented by vertical bars $(n 9-12$, with the exception of B-cells $n 5-9$ ). * Mean values were significantly different from those of healthy animals fed a standard diet $(\mathrm{REF}, \mathbb{\nabla})(P<0.05)$. † Mean values were significantly different from those of arthritic animals fed a standard diet (REF-AA, $\square)(P<0.05$; Kruskal-Wallis and Mann-Whitney $U$ tests). C5-AA, arthritic animals fed a $5 \%$ cocoa-enriched diet ( $\square$ ); C10-AA, arthritic animals fed a $10 \%$ cocoa-enriched diet ( $\square$ ).
Effect of the cocoa diet on anti-Mycobacterium butyricum antibodies in adjuvant arthritis rats

Arthritis induction, by means of heat-killed $\mathrm{Mb}$, involved the synthesis of antibodies directed against mycobacteria (Fig. 5), which are absent in non-induced animals (data not shown). The serum concentration of these antibodies increased during the arthritis time course. The intake of both cocoa diets (5 and 10\%) reduced serum anti-Mb antibody synthesis, an effect that was already detected at 2 weeks after induction $(P<0.05)$. This inhibition was dose-dependent and continued until the end of the study.

\section{Effect of the cocoa diet on ex vivo cytokine and $P G E_{2}$ secretion by splenocytes}

Splenocytes obtained on day 28 post-induction from animals of all the induced groups produced IL- 2 and IFN- $\gamma$ after the $\mathrm{Mb}$ challenge (Fig. 6(a) and (b)). IL-2 secretion was higher in splenocytes from the C5-AA and C10-AA groups than those from the REF-AA group $(P<0 \cdot 05$; Fig. 6(a)). However, cocoa did not affect IFN- $\gamma$ secretion, which was similar in all three AA groups (Fig. 6(b)).

$\mathrm{PGE}_{2}$ was secreted by splenocytes (Fig. 6(c)) from healthy and arthritic animals either without stimulus or after $\mathrm{Mb}$ addition. In non-stimulated conditions, $\mathrm{PGE}_{2}$ released by cells obtained from the C10-AA group was significantly lower than that from the REF and REF-AA groups $(P<0.05)$. However, no significant changes were observed in Mb-stimulated cells.

\section{Discussion}

In previous studies, cocoa has shown anti-inflammatory properties both in vitro and in vivo ${ }^{(22,31)}$. We have previously demonstrated that cocoa-enriched diets in young and adult animals modulate the synthesis of total and specific antibodies $^{(13,15)}$ and also decrease the proportion of $T_{h}$ cells in several lymphoid compartments ${ }^{(14)}$ in healthy conditions. On the other hand, some studies have reported the protective effect of flavonoids on arthritis models ${ }^{(37-39)}$, and specifically on adjuvant-carrageenin-induced arthritis in rats ${ }^{(40,41)}$. All these results prompted us to study the influence of long-term cocoa diets with two different dosages in a T-cell-mediated systemic inflammation model, as in $\mathrm{AA}^{(19)}$, a well-established severe polyarthritis chronic model that lasts at least 3 months ${ }^{(42)}$.

The present study shows that a cocoa-enriched diet was able to decrease the synthesis of antibodies against the pathology inducer during the progression of AA. The cocoa diet was also able to decrease the proportion of $T_{h}$ lymphocytes in blood and regional lymphoid tissues, which probably include cells responsible for the arthritic process. Moreover, the cocoa diet showed a tendency to modulate hind-paw swelling. The clinical evolution of AA in animals fed a $5 \%$ cocoa-enriched diet had a tendency to reduce the severity of the process, but unfortunately, a significant diminution of the arthritic process was not achieved through the cocoa diets. These results are in contrast with those of Pelzer and co-workers ${ }^{(40,41)}$, which showed flavonoid anti-inflammatory actions in a similar 
(a)
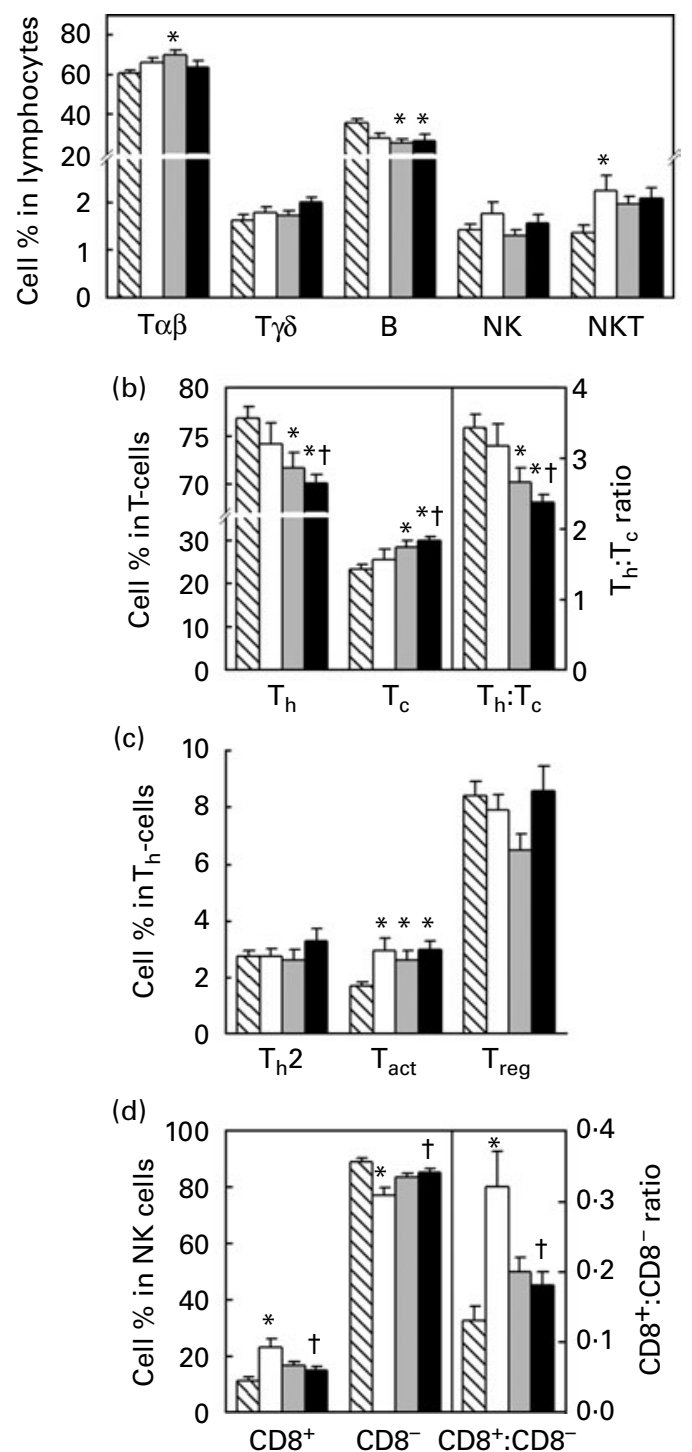

Fig. 4. Lymphocyte subset composition in rat inguinal lymph nodes, determined by double or triple staining, using fluorochrome-conjugated monoclonal antibodies followed by flow cytometry analysis. (a) $T \alpha \beta, T \gamma \delta$, B, natural killer (NK) and natural killer T (NKT) lymphocyte percentages. (b) Thelper $\left(T_{h}\right)$ and $T$-cytotoxic $\left(T_{c}\right)$ cell percentages in the T-cell population. (c) $T_{h} 2$, activated $T_{h}\left(T_{\text {act }}\right)$ and regulatory $T_{h}\left(T_{\text {reg }}\right)$ percentages in the $T_{h}$ subset. (d) $\mathrm{CD}^{+}$and $\mathrm{CD}^{-}$cell percentages in NK lymphocytes. Values are means, with their standard errors represented by vertical bars $(n 9-12)$. * Mean values were significantly different from those of healthy animals fed a standard diet $(\mathrm{REF}, \mathbb{\nabla})(P<0.05)$. † Mean values were significantly different from those of arthritic animals fed a standard diet (REF-AA, $\square)(P<0.05$; Kruskal-Wallis and Mann-Whitney $U$ tests). C5-AA, arthritic animals fed a $5 \%$ cocoa-enriched diet $(\square)$; C10-AA, arthritic animals fed a $10 \%$ cocoaenriched diet ( $\square$ )

model. However, these studies were performed by using single flavonoids (quercetin, rutin, hesperidin and morin) administered intraperitoneally, and the AA model was induced through a rather different procedure. In addition, some of these flavonoids, such as hesperidin, morin and rutin, are not even present in cocoa, and there are controversial results about the anti-inflammatory capacity of hesperidin ${ }^{(43)}$. Our results do not agree with another study that used quercetin administered orally in a rat AA model ${ }^{(44)}$. Nevertheless, the quercetin dosage used in that study was very high $(150 \mathrm{mg} / \mathrm{rat})$, while the quercetin concentration in a cocoa extract is just over $57 \mu \mathrm{g} / \mathrm{g}^{(45)}$. The lack of a clear effect in the present study could then be explained by the low proportion of quercetin in cocoa flavonoids ${ }^{(45)}$ and the daily intake of cocoa that was about $600 \mathrm{mg} / 100 \mathrm{~g}$ of rat ${ }^{(15)}$. In fact, the main and best-absorbed flavonoid in cocoa is epicatechin $^{(4)}$, a flavonoid with ascribed anti-inflammatory activities in vitro ${ }^{(22,33)}$.

Previous studies ${ }^{(13,14)}$ performed on young healthy rats showed that a $10 \%$ cocoa-enriched diet produced a decrease in $\mathrm{T}_{\mathrm{h}}$ proportion in the spleen and lymph nodes. Here, we have also showed that a cocoa diet reduces the $\mathrm{T}_{\mathrm{h}}$ proportion in the blood and ILN in AA rats. In consequence, it could be suggested that cocoa intake could entail reduction in the number of $T_{h}$ cells involved in the arthritic process ${ }^{(20)}$. However, this effect may not be enough to abolish the activity of pathogenic cells. This suggestion is in line with the concentration of IFN- $\gamma$, a pro-inflammatory cytokine, released from the splenocyte supernatants, which were similar in the three arthritic groups. IFN- $\gamma$ is a cytokine mainly produced by $\mathrm{T}_{\mathrm{act}}$ cells that enhances the inflammatory process through macrophage activation ${ }^{(46)}$.

The effect of a cocoa diet on $\mathrm{T}_{\text {reg }}$ cells is also of interest because these cells regulate immune responses ${ }^{(47)}$, and there is some evidence that patients with rheumatoid arthritis have defective $\mathrm{T}_{\text {reg }}$ cell function ${ }^{(48)}$. It has been recently reported that the transference of activated $\mathrm{T}_{\text {reg }}$ cells to mice with

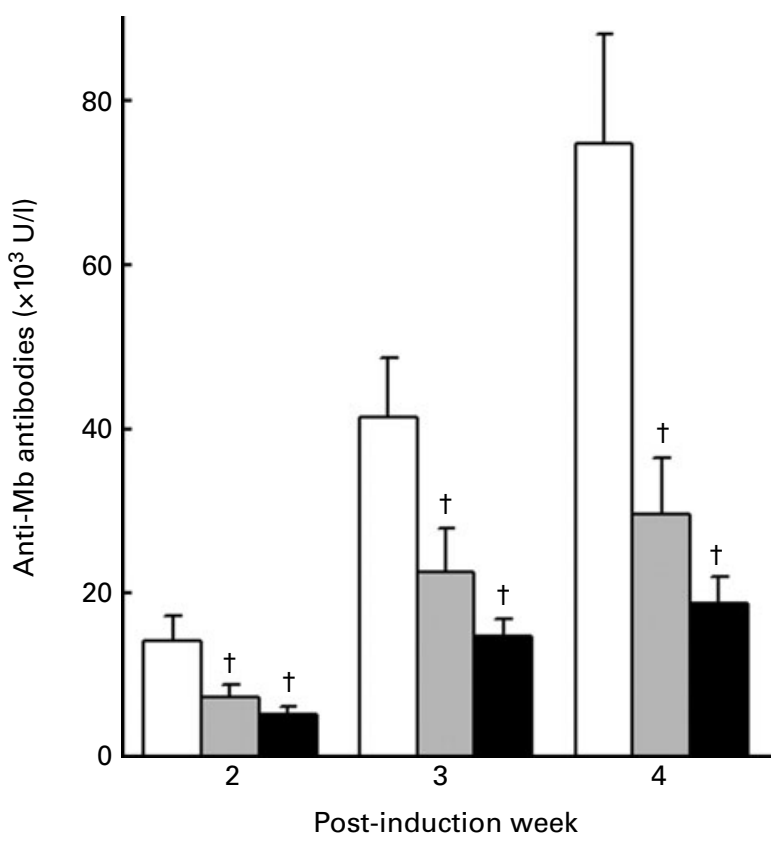

Fig. 5. Anti-Mycobacterium butyricum (Mb) antibody concentration in serum during arthritis time course. Values are means, with their standard errors represented by vertical bars $(n$ 11-12). † Mean values were significantly different from those of arthritic animals fed a standard diet (REF-AA, $\square$ ) $(P<0.05$; Kruskal-Wallis and Mann-Whitney $U$ tests). C5-AA, arthritic animals fed a $5 \%$ cocoa-enriched diet $(\square)$; C10-AA, arthritic animals fed a $10 \%$ cocoa-enriched diet ( $\mathbf{\square}$ ). 

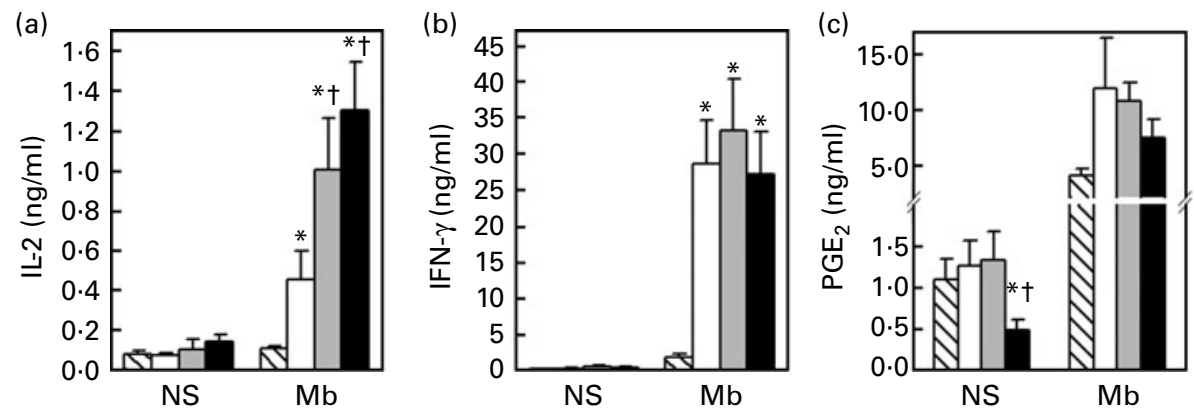

Fig. 6. Inflammatory mediator concentrations in spleen cell supernatants. (a) IL-2 concentration in the $24 \mathrm{~h}$ spleen supernatant. (b) Interferon $\gamma$ (IFN- $\gamma$ ) concentration in the $72 \mathrm{~h}$ spleen supernatant. (c) $\mathrm{PGE}_{2}$ concentration in the $48 \mathrm{~h}$ spleen supernatant. Values are means, with their standard errors represented by vertical bars $(n 10-12)$. * Mean values were significantly different from those of healthy animals fed a standard diet $(R E F, \mathbb{B})(P<0.05)$. $†$ Mean values were significantly different from those of arthritic animals fed a standard diet (REF-AA, $\square)(P<0.05$; Kruskal-Wallis and Mann-Whitney $U$ tests). NS, non-stimulated; Mb, Mycobacterium butyricum stimulated; C5-AA, arthritic animals fed a $5 \%$ cocoa-enriched diet ( $\square$ ); C10-AA, arthritic animals fed a $10 \%$ cocoa-enriched diet (ロ).

collagen-induced arthritis significantly prevented the disease development $^{(49)}$ and also slowed the arthritic progression ${ }^{(50)}$. In the present study, AA reduced the proportion of the $T_{\text {reg }}$ population in blood, but not in ILN. Interestingly, preventive consumption of a $10 \%$ cocoa-enriched diet avoided the $\mathrm{T}_{\text {reg }}$ decrease, keeping it in the healthy proportion. The increase in the $T_{\text {reg }}$ subset proportion in the C10-AA group could be due to an increase in IL-2 synthesis, because it has been reported that IL-2 favours $\mathrm{T}_{\text {reg }}$ production ${ }^{(51)}$. In the present study, an IL-2 increase was observed in splenocytes from cocoa-fed rats. In any case, the enhancement of $\mathrm{T}_{\text {reg }}$ induced in $10 \%$ cocoa-fed animals was not reflected by a decrease in $\mathrm{T}_{\mathrm{act}}$ lymphocytes, and these changes were only present in blood and not in ILN.

Another result that deserves attention is the effect of the cocoa diet on NK and NKT cells. NKT cells are immunoregulatory $\mathrm{T}$ lymphocytes that can promote cell-mediated immunity against tumours and infectious organisms but can also suppress the cell-mediated immunity associated with allograft rejection and autoimmune disease ${ }^{(52)}$. In the present study, AA increased the NKT cell percentage in ILN, and decreased that in blood. With respect to NK cells, previous studies have determined that $\mathrm{CD}^{+} \mathrm{NK}$ cells are more cytolytic than $\mathrm{CD}^{-}$NK cells and this molecule helps NK cells to survive after target cell lysis ${ }^{(53)}$. In the present study, the NK $\mathrm{CD}^{+}: \mathrm{CD}^{-}$ratio was increased in ILN from AA animals, suggesting an activation of cytolytic function in these cells by the inflammatory process. A cocoa diet prevented this disequilibrium in regional lymph nodes but this effect was not significantly reflected in articular swelling. Nevertheless, it would be interesting to understand the role of NKT and NK cells in the AA model.

Although AA is ascribed to the cellular response ${ }^{(54)}$, antibodies against the mycobacteria were developed ${ }^{(55)}$. Cocoa-enriched diets were able to decrease the levels of anti-Mb antibodies in a similar way as observed in another approach $^{(15)}$. The role of anti-Mb antibodies in the development of hind-paw swelling is negligible but a role in the late phase of arthritis has been suggested ${ }^{(55)}$. From the present results, it is clear that the reduction of the antibody proportion through cocoa intake was not enough to regulate the arthritic process during the first weeks (when articular inflammation increased), but it could explain the modulation of arthritic swelling at the 4th week. It is possible that cocoa accelerated the recuperation of this pathology by decreasing the anti-Mb antibody levels. In any case, the down-regulatory effects of antibodies due to cocoa intake could be more significant in autoimmune arthritis, both in experimental models (collagen-induced arthritis) and in human disease.

With respect to $\mathrm{PGE}_{2}$ release, an increase in its concentration has been reported in the urine of AA rats ${ }^{(56)}$, just as in human rheumatoid arthritis synovial ${ }^{(57)}$. Here, we show that a cocoa diet reduced splenocyte $\mathrm{PGE}_{2}$ production in the C10-AA group. As macrophage is the main source of $\mathrm{PGE}_{2}$ during inflammation ${ }^{(58)}$, the $\mathrm{PGE}_{2}$ reduction found here correlates with previous results, showing that peritoneal macrophages from animals fed cocoa produced lower amounts of other pro-inflammatory mediators such as IL-6, TNF- $\alpha$ and NO ex vivo ${ }^{(31,32)}$.

From the results obtained in the present study, it can be concluded that cocoa intake reduces the $\mathrm{T}_{\mathrm{h}}$-cell proportion and modulates some alterations induced by the arthritic process, such as a decrease in the blood $\mathrm{T}_{\text {reg }}$ cell percentage and a disequilibrium in inguinal NK cells. Moreover, a cocoa diet reduces the anti-Mb antibody concentration in sera and diminishes spleen $\mathrm{PGE}_{2}$ production. These changes are not enough to significantly decrease chronic articular swelling, although a tendency to its modulation is observed at the end of the study. Finally, we can conclude that a cocoa diet channels the organism to develop an 'anti-inflammatory environment'. Other studies need to be performed in order to establish the effect of cocoa in autoimmune arthritic models and its potential as an accompaniment of anti-inflammatory drugs.

\section{Acknowledgements}

The present study was supported by the Ministerio de Educación y Ciencia, Spain (AGL2005-002823), the Ministerio de Sanidad y Consumo (CIBER 06/02/0079) and by the Generalitat de Catalunya, Spain (SGR 2005-0083). S. R.-R. is the recipient of a fellowship from the Ministerio de Educación y Ciencia, Spain (BES-2006-13640). The authors declare they have no competing interests. S. R.-R. carried out the study, performed 
the statistical analysis and drafted the manuscript. F. J. P.-C. and C. C. collaborated during the in vivo part and in the discussion of the results. M. C. and A. F. designed, supervised and coordinated the study. All the authors read and approved the final manuscript. The authors would like to thank the 'Serveis Científico-Tècnics' of the University of Barcelona, especially Dr J. Comas, for expert assistance in flow cytometry.

\section{References}

1. Hurst WJ, Tarka SM Jr, Powis TG, et al. (2002) Cacao usage by the earliest Maya civilization. Nature 418, 289-290.

2. Pucciarelli DL \& Grivetti LE (2008) The medicinal use of chocolate in early North America. Mol Nutr Food Res 52, 1215-1227.

3. Keen CL (2001) Chocolate: food as medicine/medicine as food. J Am Coll Nutr 20, 436S-439S.

4. Rusconi M \& Conti A (2010) Theobroma cacao L., the food of the gods: a scientific approach beyond myths and claims. Pharmacol Res 61, 5-13.

5. Gu L, House SE, Wu X, et al. (2006) Procyanidin and catechin contents and antioxidant capacity of cocoa and chocolate products. J Agric Food Chem 54, 4057-4061.

6. Tomas-Barberan FA, Cienfuegos-Jovellanos E, Marín A, et al. (2007) A new process to develop a cocoa powder with higher flavonoid monomer content and enhanced bioavailability in healthy humans. J Agric Food Chem 55 , 3926-3935.

7. Natsume M, Osakabe N, Yamagishi M, et al. (2000) Analyses of polyphenols in cacao liquor, cocoa, and chocolate by normal-phase and reversed-phase HPLC. Biosci Biotechnol Biochem 64, 2581-2587.

8. Monagas M, Urpi-Sarda M, Sánchez-Patán F, et al. (2010) Insights into the metabolism and microbial biotransformation of dietary flavan-3-ols and the bioactivity of their metabolites. Food Funct 1, 233-253.

9. Aura AM (2008) Microbial metabolism of dietary phenolic compounds in the colon. Phytochem Rev 7, 407-429.

10. Selma MV, Espín JC \& Tomás-Barberán FA (2009) Interaction between phenolics and gut microbiota: role in human health. J Agric Food Chem 57, 6485-6501.

11. Manach C, Scalbert A, Morand C, et al. (2004) Polyphenols: food sources and bioavailability. Am J Clin Nutr 79 , $727-747$.

12. Sánchez-Rabaneda F, Jáuregui O, Casals I, et al. (2003) Liquid chromatographic/electrospray ionization tandem mass spectrometric study of the phenolic composition of cocoa (Theobroma cacao). J Mass Spectrom 38, 35-42.

13. Ramiro-Puig E, Pérez-Cano FJ, Ramírez-Santana C, et al. (2007) Spleen lymphocyte function modulated by a cocoaenriched diet. Clin Exp Immunol 149, 535-542.

14. Ramiro-Puig E, Pérez-Cano FJ, Ramos-Romero S, et al. (2008) Intestinal immune system of young rats influenced by cocoaenriched diet. J Nutr Biochem 19, 555-565.

15. Pérez-Berezo T, Ramiro-Puig E, Pérez-Cano FJ, et al. (2009) Influence of a cocoa-enriched diet on specific immune response in ovalbumin-sensitized rats. Mol Nutr Food Res 53, 389-397.

16. Chen G (2010) Immunotherapy of rheumatoid arthritis targeting inflammatory cytokines and autoreactive $\mathrm{T}$ cells. Arch Immunol Ther Exp (Warsz) 58, 27-36.

17. Waksman BH (2002) Immune regulation in adjuvant disease and other arthritis models: relevance to pathogenesis of chronic arthritis. Scand J Immunol 56, 12-34.
18. Holmdahl R, Lorentzen JC, Lu S, et al. (2001) Arthritis induced in rats with non-immunogenic adjuvants as models for rheumatoid arthritis. Immunol Rev 184, 184-202.

19. Pelegrí C, Morante MP, Castellote C, et al. (1995) Administration of a nondepleting anti-CD4 monoclonal antibody (W3/25) prevents adjuvant arthritis, even upon rechallenge: parallel administration of a depleting anti-CD8 monoclonal antibody (OX8) does not modify the effect of W3/25. Cell Immunol 165, 177-182.

20. Pelegrí C, Morante MP, Castellote C, et al. (1996) Treatment with an anti-CD4 monoclonal antibody strongly ameliorates established rat adjuvant arthritis. Clin Exp Immunol 103, 273-278.

21. Medzhitov R (2008) Origin and physiological roles of inflammation. Nature 454, 428-435.

22. Ramiro E, Franch A, Castellote C, et al. (2005) Flavonoids from Theobroma cacao down-regulate inflammatory mediators. J Agric Food Chem 53, 8506-8511.

23. García-Mediavilla V, Crespo I, Collado PS, et al. (2007) The anti-inflammatory flavones quercetin and kaempferol cause inhibition of inducible nitric oxide synthase, cyclooxygenase-2 and reactive C-protein, and down-regulation of the nuclear factor kappaB pathway in Chang Liver cells. Eur J Pharmacol 557, 221-229.

24. de Pascual-Teresa S, Johnston KL, DuPont MS, et al. (2004) Quercetin metabolites downregulate cyclooxygenase-2 transcription in human lymphocytes ex vivo but not in vivo. J Nutr 134, 552-557.

25. Matsuoka Y, Hasegawa H, Okuda S, et al. (1995) Ameliorative effects of tea catechins on active oxygen-related nerve cell injuries. J Pharmacol Exp Ther 274, 602-608.

26. Mao TK, van de Water J, Keen CL, et al. (2002) Modulation of TNF-alpha secretion in peripheral blood mononuclear cells by cocoa flavanols and procyanidins. Dev Immunol $\mathbf{9}$, 135-141.

27. Kenny TP, Keen CL, Schmitz HH, et al. (2007) Immune effects of cocoa procyanidin oligomers on peripheral blood mononuclear cells. Exp Biol Med (Maywood) 232, 293-300.

28. Wisman KN, Perkins AA, Jeffers MD, et al. (2008) Accurate assessment of the bioactivities of redox-active polyphenolics in cell culture. J Agric Food Chem 56, 7831-7837.

29. Jenny M, Santer E, Klein A, et al. (2009) Cacao extracts suppress tryptophan degradation of mitogen-stimulated peripheral blood mononuclear cells. J Ethnopharmacol 122, 261-267.

30. Ramos-Romero S, Ramiro-Puig E, Pérez-Cano FJ, et al. (2008) Anti-inflammatory effects of cocoa in rat carrageenininduced paw oedema. Proc Nutr Soc 67, E65.

31. Castell M, Franch A, Ramos-Romero S, et al. (2009) Effect of a diet rich in cocoa flavonoids on experimental acute inflammation. In Flavonoids: Biosynthesis, Biological Effects and Dietary Sources, 1st ed., pp. 213-229 [RB Keller, editor]. Hauppauge: Nova Science Publishers, Inc.

32. Ramos-Romero S, Pérez-Cano FJ, Pérez-Berezo T, et al. (2010) A seven-day high cocoa diet decreases oxidant and inflammatory properties of peritoneal macrophages in rats. Proc Nutr Soc 69, E253.

33. Mackenzie GG, Carrasquedo F, Delfino JM, et al. (2004) Epicatechin, catechin, and dimeric procyanidins inhibit PMA-induced NF-kappaB activation at multiple steps in Jurkat T cells. FASEB J 18, 167-169.

34. Comalada M, Camuesco D, Sierra S, et al. (2005) In vivo quercitrin anti-inflammatory effect involves release of quercetin, which inhibits inflammation through down-regulation of the NF-кB pathway. Eur J Immunol 35, 584-592. 
35. Reagan-Shaw S, Nihal M \& Ahmad N (2008) Dose translation from animal to human studies revisited. FASEB $J \mathbf{2 2}$, 659-661.

36. Franch A, Cassany S, Castellote C, et al. (1992) Adjuvant arthritis pretreatment with type II collagen and Mycobacterium butyricum. Immunobiology 186, 351-361.

37. Li R, Cai L, Xie XF, et al. (2010) Hesperidin suppresses adjuvant arthritis in rats by inhibiting synoviocyte activity. Phytother Res 24, S71-S76.

38. Kawaguchi K, Maruyama H, Kometani T, et al. (2006) Suppression of collagen-induced arthritis by oral administration of the citrus flavonoid hesperidin. Planta Med 72, 477-479.

39. Haqqi TM, Anthony DD, Gupta S, et al. (1999) Prevention of collagen-induced arthritis in mice by a polyphenolic fraction from green tea. Proc Natl Acad Sci USA 96, 4524-4529.

40. Guardia T, Rotelli AE, Juarez AO, et al. (2001) Anti-inflammatory properties of plant flavonoids. Effects of rutin, quercetin and hesperidin on adjuvant arthritis in rat. Farmaco $\mathbf{5 6}$, 683-687.

41. Rotelli AE, Guardia T, Juárez AO, et al. (2003) Comparative study of flavonoids in experimental models of inflammation. Pharmacol Res 48, 601-606.

42. Franch A, Castellote C \& Castell C (1994) Anti-type I collagen antibodies in advanced phases of adjuvant arthritis. Path Res Pract 190, 155-158.

43. Rovenský J, Stančíková M, Rovenská E, et al. (2009) Treatment of rat adjuvant arthritis with flavonoid (Detralex), methotrexate, and their combination. Ann N Y Acad Sci 1173, 798-804.

44. Mamani-Matsuda M, Kauss T, Al-Kharrat A, et al. (2006) Therapeutic and preventive properties of quercetin in experimental arthritis correlate with decreased macrophage inflammatory mediators. Biochem Pharmacol $\mathbf{7 2}$, $1304-1310$.

45. Ortega N, Romero MP, Macià A, et al. (2008) Obtention and characterization of phenolic extracts from different cocoa sources. J Agric Food Chem 56, 9621-9627.
46. Saha B, Jyothi Prasanna S, Chandrasekar B, et al. (2010) Gene modulation and immunoregulatory roles of interferon $\gamma$. Cytokine 50, 1-14.

47. Belkaid Y \& Rouse BT (2005) Natural regulatory T cells in infectious disease. Nat Immunol 6, 353-360.

48. Sarkar S \& Fox DA (2007) Regulatory T cell defects in rheumatoid arthritis. Arthritis Rheum 56, 710-713.

49. Kelchtermans H, Geboes L, Mitera T, et al. (2009) Activated CD $4+$ CD25 + regulatory T cells inhibit osteoclastogenesis and collagen-induced arthritis. Ann Rheum Dis 68, 744-750.

50. Morgan ME, Flierman R, van Duivenvoorde LM, et al. (2005) Effective treatment of collagen-induced arthritis by adoptive transfer of CD25 + regulatory T cells. Arthritis Rheum 52, 2212-2221.

51. Malek TR, Yu A, Zhu L, et al. (2008) IL-2 family of cytokines in $\mathrm{T}$ regulatory cell development and homeostasis. J Clin Immunol 28, 635-639.

52. Godfrey DI, Stankovic S \& Baxter AG (2010) Raising the NKT cell family. Nat Immunol 11, 197-206.

53. Addison EG, North J, Bakhsh I, et al. (2005) Ligation of CD8 $\alpha$ on human natural killer cells prevents activation-induced apoptosis and enhances cytolytic activity. Immunology 116, 354-361.

54. Van Eden W \& Waksman BH (2003) Immune regulation in adjuvant-induced arthritis: possible implications for innovative therapeutic strategies in arthritis. Arthritis Rheum $\mathbf{4 8}$, 1788-1796.

55. Franch A, Castellote C \& Castell M (1994) Effect of acetylsalicylic acid and dexamethasone on antibody production in adjuvant arthritis. Rheumatol Int 14, 27-31.

56. Honda H, Fukawa K \& Sawabe T (1980) Influence of adjuvant arthritis in main urinary metabolites of prostaglandin $\mathrm{F}$ and $\mathrm{E}$ in rats. Prostaglandins 19, 259-269.

57. Goetzl EJ, An S \& Smith WL (1995) Specificity of expression and effects of eicosanoid mediators in normal physiology and human diseases. FASEB J 9, 1051-1058.

58. Humes JL, Bonney RJ, Pelus L, et al. (1977) Macrophages synthesis and release prostaglandins in response to inflammatory stimuli. Nature 269, 149-151. 